E3S Web of Conferences 1, 07009 (2013)

DOI: $10.1051 / \mathrm{e} 3$ sconf/20130107009

(c) Owned by the authors, published by EDP Sciences, 2013

\title{
Decreasing trends in total gaseous mercury observations in baseline air at Mace Head, Ireland from 1996 to 2011
}

\author{
R. Ebinghaus ${ }^{1}$, S. G. Jennings ${ }^{2}$, H. H. Kock ${ }^{1}$, R. G. Derwent ${ }^{3}$, A. J. Manning ${ }^{4}$, T. G. Spain ${ }^{2}$ and A. Weigelt ${ }^{1}$ \\ ${ }^{1}$ Helmholtz-Zentrum Geesthacht, Institute of Coastal Research, Max-Planck-Str. 1, D-21502 Geesthacht, Germany, \\ Ralf.Ebinghaus@hzg.de; Andreas.Weigelt@hzg.de \\ ${ }^{2}$ School of Physics, National University of Ireland, Galway, Ireland \\ ${ }^{3}$ rdscientific, Newbury, Berkshire, United Kingdom \\ ${ }^{4}$ Met Office, Exeter, United Kingdom
}

\begin{abstract}
The Mace Head dataset comprises the longest existing time series of atmospheric mercury measurements with high time resolution in the temperate marine background atmosphere, starting in September 1995. For this study, the concentrations of total gaseous mercury in baseline air masses arriving at Mace Head, Ireland have been analyzed for possible trends in the atmospheric mercury background concentration over a 16-year period (i.e., 1996-2011). Statistical analyses have revealed a significant negative (downwards) trend of $-0.027+/-0.01 \mathrm{ng} / \mathrm{m}^{3} \mathrm{yr}^{-1}$, or -1.4 to $1.8 \%$ per year. Furthermore, evidence of a seasonal cycle was found with somewhat higher concentrations during the winter time and somewhat lower concentrations during summer.
\end{abstract}

Key words: Total gaseous mercury, Long term trends, Mace Head, Hg, GMOS

\section{Introduction}

Mercury $(\mathrm{Hg})$ is emitted into the atmosphere from a variety of anthropogenic and natural sources. Of the anthropogenic sources, the most important are fossil fuel combustion, smelting, cement production and waste incineration (Pirrone et al., 2009; Pacyna et al., $2006 ; 2010)$. The oceans are the largest natural source of $\mathrm{Hg}$ to the atmosphere; however volcanic emissions are suspected sources as well (Pirrone et al., 2009; Ferrara et al., 2000; Masson 2009). It has been suggested that due to intensified anthropogenic emissions of mercury since the beginning of the industrialization, the global atmospheric burden has increased over the past 150 years. Recent analyses of lake sediments, ice cores, peat deposits, and firn air records have revealed evidence of long-term changes in the atmospheric mercury burden (cf. references given in Ebinghaus et al., 2011). These studies identify a peak in the atmospheric mercury concentration during the 1970's in the Northern Hemisphere. Intensive efforts have been undertaken especially in Europe and North America to reduce mercury emissions (Wangberg et al., 2007). This reduction however is believed to be compensated or even surpassed by strongly increasing emissions in rapidly industrialising countries (Pacyna et al., 2010).
The Mace Head dataset comprises the longest existing time series of atmospheric mercury measurements with high time resolution in the temperate marine background atmosphere. The measurements started in September 1995, sometime after the Alert station began making mercury observations in Arctic Canada. Within this study, hourly attribution of air mass origins has been conducted to understand the sources that contribute to the observed levels at Mace Head. Classification of air masses can be done e.g. by meteorological analysis (Manning et al., 2003). Total gaseous mercury (TGM) baseline concentrations at Mace Head have been estimated, based on hourly concentration averages using meteorological analyses and a Lagrangian dispersion model. These baseline data are considered to be representative of the unpolluted Northern Hemisphere and have been used to determine trends in the TGM concentrations over the 1995-2009 period (Ebinghaus et al. 2011). This presentation will up-date the existing analysis by the years 2010 and 2011.

\section{Materials and Methods}

Measurement Location 


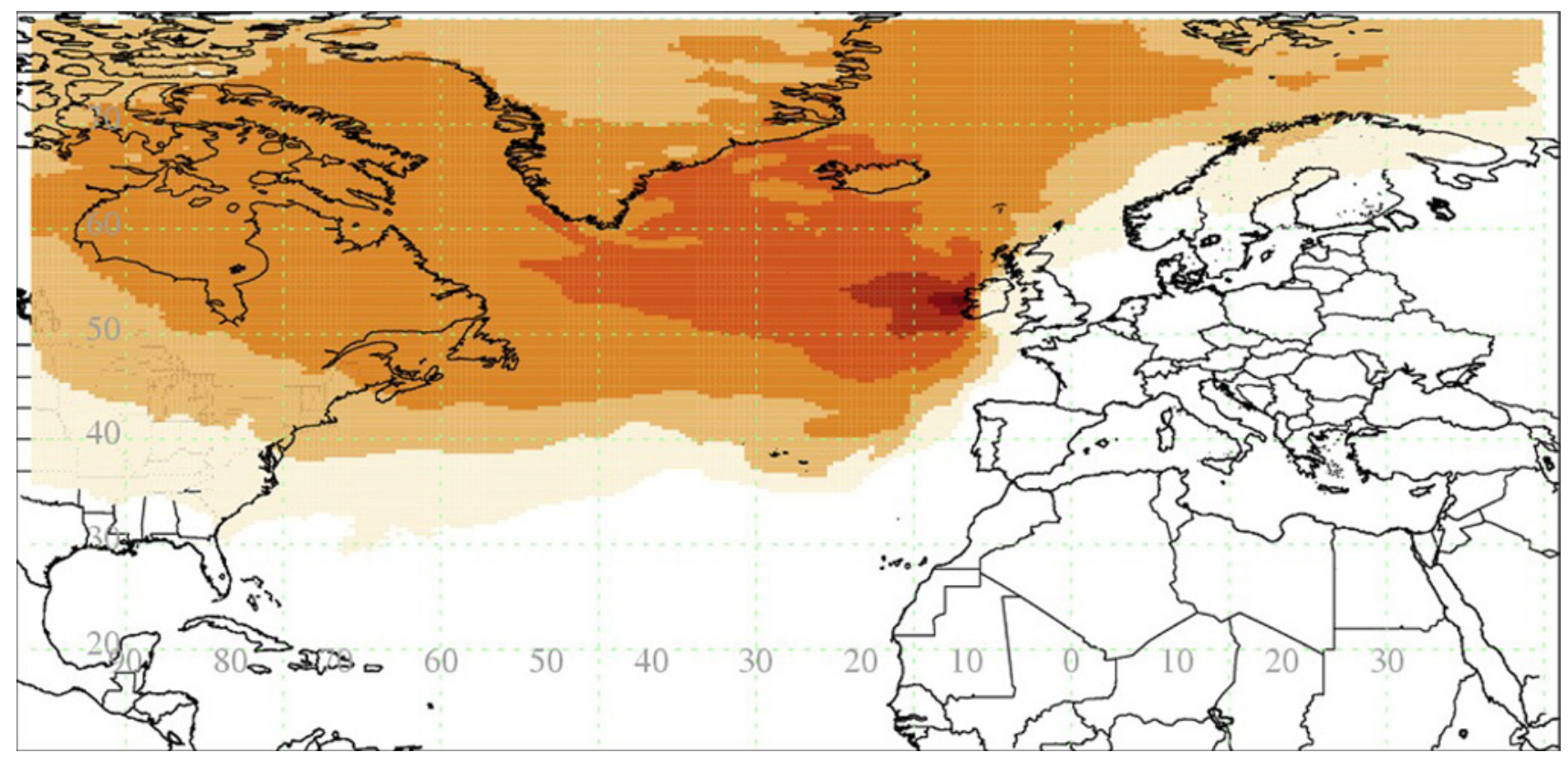

Fig. 1. A composite of the back-attribution plots for Mace Head, Ireland for all air masses assigned to the baseline category during 1998, with the pixel colours showing the relative contribution to the air concentration at Mace Head, Ireland from the emissions of an inert tracer at that location.

Mace Head is located on the west coast of Ireland at $53^{\circ}$ $20^{\prime} \mathrm{N} ; 9^{\circ} 54^{\prime} \mathrm{W}$. It is exposed to the North Atlantic Ocean. The meteorological records show that about $50 \%$ of the air masses arriving at Mace Head are within the clean sector and have recently traversed the thousands of kilometres of uninterrupted fetch across the North Atlantic Ocean. There is no industrial activity which would influence measurements at the station within about $90 \mathrm{~km}$ of the site and the nearest major conurbation of Galway city is located $90 \mathrm{~km}$ east of Mace Head.

The automatic mercury measurements were performed using a Tekran mercury analyzer (model 2537A; www.tekran.com). The measurement principle of the $2537 \mathrm{~A}$ is based on cold vapor atomic flourescence spectroscopy (CVAFS). The temporal resolution was set to 15 minutes with auto calibration measurements every 25 hours. Detailed information to the operation of the Tekran 2537A can be found in Ebinghaus at al. (2011), or at www.tekran.com.

To determine trends in total gaseous mercury (TGM) observations, it is important to select air masses that are representative of the unpolluted Northern Hemispheric marine boundary layer. The TGM levels monitored in these air masses are referred to as baseline levels (baseline air) and by definition they should have not been influenced by recent, local or regional emissions. In this study, an atmospheric dispersion modelling method ('NAME' Lagrangian dispersion model; Ryall et al., 1998) has been employed to separate baseline air measurements. The NAME model uses three-hourly three-dimensional meteorology fields from complex meteorological weather prediction models to move abstract air parcels around a model domain. The three- dimensional model flow is interpolated to each parcel location at each 15-minute time step. Using a random walk technique, each parcel moves under the influence of the mean flow, wind meander, and sub-grid scale turbulence. The random walk scheme uses velocity variance and Lagrangian timescale profiles determined from empirical fits to observational data to simulate the turbulent motion and are described more detail in Ryall and Maryon (1998) and Ryall et al. (1998).

The model has been further refined, using a backattribution technique (Manning et al., 2003). Therefore an inert tracer is released uniformly across a three-hour period from Mace Head and followed backwards in time. Figure 1 shows as an example a composite of all air mass history maps assigned to the baseline category for 1998 . The colours of the pixels indicate the contribution to the air concentration at Mace Head from emissions at that point, with deeper colours showing larger contributions. In this way it is ensured, the transport was intercontinental in scale for all periods allocated to the baseline category.

The NAME model was operated in backward mode to estimate the impact of surface sources (assumed within $100 \mathrm{~m}$ of the ground) within 12 days of travel en-route to Mace Head. The computational domain covered $100^{\circ} \mathrm{W}$ to $45.125^{\circ} \mathrm{E}$ and $10^{\circ} \mathrm{N}$ to $80.125^{\circ} \mathrm{N}$ and extended to more than $10 \mathrm{~km}$ vertically. For each 3-hour period, 33,000 inert model particles were used to describe the atmospheric dispersion. Baseline concentrations are defined as those that have not been influenced by significant regional emissions, i.e., those that are wellmixed and are representative of the mid-latitude of the northern hemisphere. A 3-hour period is classed as 
Table 1. Monthly average concentrations $\left(\mathrm{ng} / \mathrm{m}^{3}\right)$ of total gaseous mercury in baseline air masses arriving at Mace Head, Ireland for the period from February 1996 to December 2011.

\begin{tabular}{|l|l|l|l|l|l|l|l|l|l|l|l|l|}
\hline Year & Jan & Feb & Mar & Apr & May & Jun & \multicolumn{1}{l|}{ Jul } & \multicolumn{1}{l|}{ Aug } & Sep & \multicolumn{1}{l|}{ Oct } & Nov & Dec \\
\hline $\mathbf{1 9 9 6}$ & & 1.55 & 2.60 & 2.06 & 1.59 & 1.88 & 1.94 & 1.71 & 1.66 & 1.62 & 2.20 & 1.80 \\
\hline $\mathbf{1 9 9 7}$ & 1.76 & 1.90 & 1.70 & 1.85 & 1.55 & 1.55 & 1.54 & & & & & \\
\hline $\mathbf{1 9 9 8}$ & & & & & 1.63 & 1.68 & 1.59 & 1.66 & 1.51 & 1.93 & 1.98 & 2.00 \\
\hline $\mathbf{1 9 9 9}$ & 2.00 & 1.79 & 1.92 & 1.68 & 1.56 & 1.69 & 1.58 & 1.45 & 1.51 & 1.69 & 1.96 & 2.12 \\
\hline $\mathbf{2 0 0 0}$ & 1.95 & 1.90 & 1.97 & 2.11 & 1.91 & 1.74 & 1.63 & 1.69 & 1.57 & 1.67 & 1.68 & 1.67 \\
\hline $\mathbf{2 0 0 1}$ & 1.60 & 1.57 & 1.73 & 1.92 & 1.61 & 1.54 & 1.62 & 1.52 & 1.54 & 1.66 & 1.63 & 1.56 \\
\hline $\mathbf{2 0 0 2}$ & 1.87 & 1.87 & 1.80 & 1.90 & 1.82 & 1.67 & 1.42 & 1.46 & 1.75 & 1.59 & 1.75 & 1.87 \\
\hline $\mathbf{2 0 0 3}$ & 1.65 & 1.65 & 1.73 & 1.53 & 1.52 & 1.59 & 1.63 & 1.68 & 1.50 & 1.57 & 1.75 & 1.82 \\
\hline $\mathbf{2 0 0 4}$ & 1.63 & 1.79 & 1.77 & 1.55 & 1.60 & 1.63 & 1.60 & 1.43 & 1.56 & 1.53 & 1.59 & 1.64 \\
\hline $\mathbf{2 0 0 5}$ & & & & & 1.55 & 1.66 & 1.61 & 1.59 & 1.49 & 1.47 & 1.53 & 1.53 \\
\hline $\mathbf{2 0 0 6}$ & 1.55 & 1.62 & 1.59 & 1.57 & 1.44 & 1.38 & 1.41 & 1.31 & 1.25 & 1.46 & 1.58 & 1.55 \\
\hline $\mathbf{2 0 0 7}$ & 1.61 & 1.56 & 1.60 & 1.75 & 1.74 & 1.59 & 1.52 & 1.48 & 1.56 & 1.47 & 1.58 & 1.59 \\
\hline $\mathbf{2 0 0 8}$ & 1.77 & 1.68 & 1.62 & 1.57 & 1.56 & 1.55 & 1.59 & 1.46 & 1.39 & 1.50 & 1.56 & 1.44 \\
\hline $\mathbf{2 0 0 9}$ & 1.43 & 1.53 & 1.51 & 1.53 & 1.37 & 1.35 & 1.39 & 1.38 & 1.33 & 1.29 & 1.40 & 1.45 \\
\hline $\mathbf{2 0 1 0}$ & 1.51 & 1.54 & 1.43 & 1.41 & 1.44 & 1.47 & 1.42 & 1.41 & 1.32 & 1.29 & 1.47 & 1.58 \\
\hline $\mathbf{2 0 1 1}$ & 1.70 & 1.68 & 1.43 & 1.26 & 1.43 & 1.30 & 1.72 & 1.58 & 1.46 & 1.37 & 1.24 & 1.34 \\
\hline
\end{tabular}

'baseline' if recent emissions from Europe or local to Mace Head would not significantly contribute or if there is significant influence from southerly latitudes. The 'local' criterion is designed to exclude low wind and stable boundary layer situations when local topographic or heating effects can result in complex wind features, e.g., land or sea breezes, which are not resolved by the underpinning NAME meteorology and when an emission local to Mace Head would have a significant influence on observations. Southerly air masses are excluded because of the impact of potentially strong hemispheric gradients.

\section{Results}

The air masses, assigned to the baseline category on an hourly basis, were extracted from the complete dataset to form a baseline meteorological dataset. The hourly average TGM observations were then abstracted from this baseline dataset to form a baseline TGM dataset for the baseline hours only. Over the 16 year period of this study, a total of 45,158 TGM observations were assigned to baseline air masses, representing a data capture of $28.6 \%$, somewhat lower than the maximum possible of about $50 \%$ because of the limited data capture of the TGM instrument over the extended period. Calendar month averages for TGM were then calculated for baseline air masses from the hourly values. These monthly averages are tabulated in Table 1. No lower limit value was set on the number of hourly observations needed to characterise a valid monthly average. Figure 2 shows the monthly mean baseline TGM values as a time series.

The seasonal cycle obtained by averaging all the January, then February and so on, monthly mean TGM levels over the period from February 1996 to December 2011 is shown in Fig. 3. This averaged monthly baseline

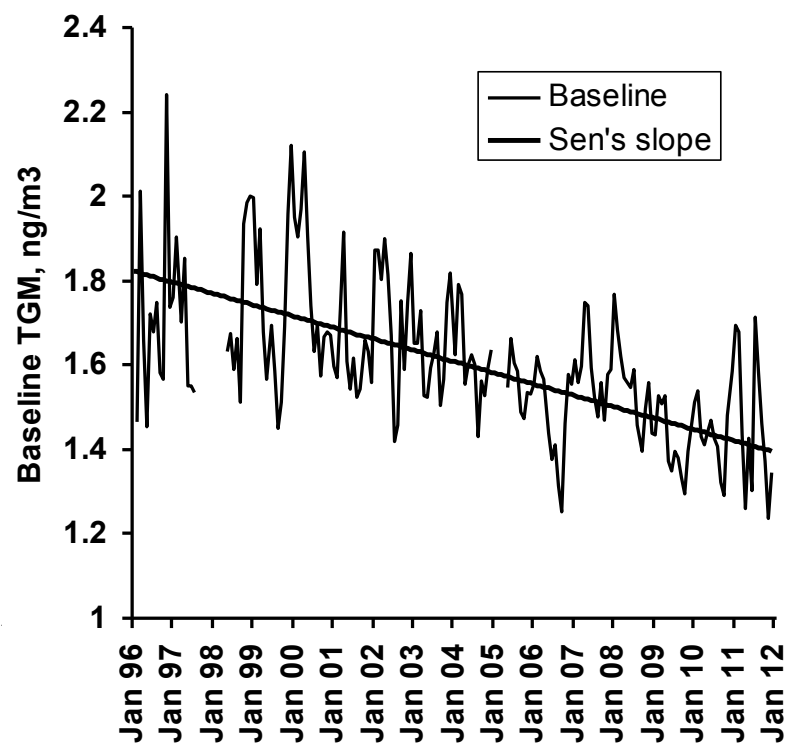

Fig. 2. Time series of monthly mean baseline TGM levels at Mace Head, Ireland over the period from 1996 to 2011, also showing the fitted trend based on the MannKendall test and Sen's slope.

period from November to April and somewhat lower levels during May to October. Such seasonal cycles appear to be consistent with those observed at Mace Head, Ireland for a wide variety of trace gases. It is suggested that meteorological, seasonal variability is the most important factor in the establishment of the observed seasonal cycle of the TGM concentrations. Temporal dynamics of TGM are complex, with the magnitude of diurnal and seasonal changes often being larger than annual changes. 
The presence of trends was investigated with the application of the Mann-Kendall test and Sen's slope estimate (Salmi et al., 2002) to the monthly baseline levels in Table 1. Annual baseline TGM means decreased from $1.82 \mathrm{ng} / \mathrm{m}^{3}$ at the start of the record in 1996 to 1.40 $\mathrm{ng} / \mathrm{m}^{3}$ in 2011 (Fig. 2). They showed a highly statistically significant negative (downwards) trend of -0.027 $+/-0.01 \mathrm{ng} / \mathrm{m}^{3} \mathrm{yr}^{-1}$ (at the $99.9 \%$ level of significance), which is $1.4-1.8 \%$ per year or $26 \%$ in 16 years of investigation.

\section{Acknowledgements}

RGD, AJM and the operation of the Mace Head station was supported by the Climate and Energy: Science and Analysis Division of the Department for Energy and Climate Change UK, under contracts EPG 1/1/130 and 142, CPEG 11, 24 and 27, GA 01081, GA0201 and CESA 002.

The Irish Environmental Protection Agency, through its Climate Change Research Programme is acknowledged for the support of the mercury measurement programme at Mace Head.

\section{References}

Ebinghaus, R., S.G. Jennings, H.H. Kock, R.G. Derwent, A.J. Manning, T.G. Spain, 2011, Decreasing trends in total gaseous mercury in baseline air at Mace Head, Ireland from 1996 to 2009, Atmospheric Environment, 45, 3475-3480.

Ferrara, R., et al., 2000. Volcanoes as emission sources of atmospheric mercury in the Mediterranean basin. The Science of the Total Environment, 259, 115121.

Manning, A.J., Ryall, D.B., Derwent, R.G., Simmonds, P.G., O’Doherty, S., 2003. Estimating European emissions of ozone-depleting and greenhouse gases using observations and a modeling back-attribution technique. Journal of Geophysical Research 108, D4405. doi:10.1029/2002JD002312.

Mason, R.P., 2009. Mercury emissions from natural processes and their importance in the global mercury cycle. In: Pirrone, N., Mason, R.P. (Eds.), Mercury Fate and Transport in the Global Atmosphere. Springer, Dordrecht.

Pacyna, E.G., Pacyna, J.M., Sundseth, K., Munthe, J., Kindborn, K., Wilson, S., Steenhuisen, F., Maxson, P., 2010. Global emission of mercury to the atmosphere from anthropogenic sources in 2005 and projections to 2020. Atmospheric Environment 44, 2487-2499.

Pacyna, E., Pacyna, J.M., Steenhuisen, F., Wilson, S., 2006. Global anthropogenic mercury emission inventory for 2000. Atmospheric Environment 40, 4048-4063.

Pirrone, N., et al., 2009. Global mercury emissions to the atmosphere from natural and anthropogenic sources. In: Pirrone, N., Mason, R.P. (Eds.), Mercury Fate and Transport in the Global Atmosphere: Emissions, Measurements, and Models. Springer, pp. 3-49.

Ryall, D.B., Maryon, R.H., 1998. Validation of the UK Met Office's NAME model against the ETEX dataset. Atmospheric Environment 32, 4265-4276.

Ryall, D.B., Maryon, R.H., Derwent, R.G., Simmonds, P.G., 1998. Modelling long-range transport of CFCs to Mace Head, Ireland. Quarterly Journal of the Royal Meteorological Society 124, 417-446.

Salmi, T., Maata, A., Antilla, P., Ruoho-Airola, T., Amnell, T., 2002. Detecting Trends of Annual Values of Atmospheric Pollutants by the MannKendall Test and Sen's Slope Estimates - The Excel Template Application Makesens. Finnish Meteorological Institute, Helsinki, Finland.

Wangberg, I., Munthe, J., Berg, T., Ebinghaus, R., Kock, H.H., Temme, C., Bieber, E., Spain, T.G., Stolk, A., 2007. Trends in air concentration and deposition of mercury in the coastal environment of the North Sea. Atmospheric Environment, 41, 2612-2619. 